YАK 616.155.1-008.1

DOI: 10.24884/1682-6655-2021-20-1-77-83

А. А.ФАБРИЧНОВА ${ }^{1}$, В.Б. КОШЕАЕВ², И.В.МИСНИКОВА², Ю. А. КОВАМЕВА ${ }^{2}$, А. Н. СЕМЕНОВ ${ }^{1}$, А. Е. АУГОВЦОВ ${ }^{1}$,

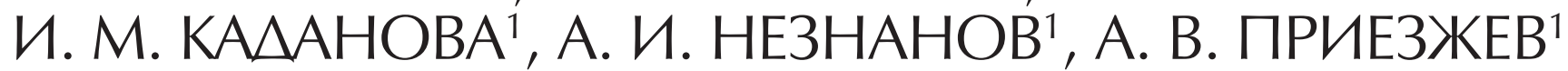
Исследование сил парного взаимодействия эритроцитов при их агрегации методом оптического захвата
при сахарном диабете 1 и 2 типов

1 Федеральное государственное бюджетное образовательное учреждение высшего образования «Московский государственный университет имени М. В. Аомоносова», Москва, Россия

119991, Россия, Москва, Аенинские горы, м. 1

2 Государственное бюджетное учреждение зАравоохранения Московской области «Московский областной научно-исследовательский кминический институт имени М. Ф. ВАахимирского», Москва, Россия 129110, Россия, Москва, ум. Шепкина, м. 61/2, корп. 1

E-mail: anastasia.fabrichnova@mail.ru

Резюме

Статья поступила в редакцию 30.11.20; принята к печати 15.01.21

Цель - измерение и сравнение сил агрегации и дезагрегации отдельных эритроцитов при образовании или развале парного агрегата in vitro в крови больных сахарным диабетом 1 типа (СД1) и сахарным диабетом 2 типа (СД2), используя метод оптического захвата. Материалы и методы. Всего в исследование были включены 50 человек. Из них 10 человек с СД1 (в возрасте $28 \pm 15,8$ года), 26 человек с СД2 (в возрасте $66 \pm 13$ лет). Группу контроля составили 14 практически здоровых добровольцев (46 21 год). Измерения сил парного взаимодействия эритроцитов в разбавленной суспензии проводились in vitro методом двухканального оптического захвата. Измерялась сила агрегации эритроцитов $\mathrm{F}_{\mathrm{A}}($ пН), сила дезагрегации $\mathrm{F}_{\mathrm{D}}\left(\right.$ пН) и вычислялось отношение сил $\mathrm{F}_{\mathrm{D}} / \mathrm{F}_{\mathrm{A}}$. Результаты. Значение сил агрегации эритроцитов значимо не отличалось в группе СД1 от группы контроля. Однако силы дезагрегации в группе СД1 оказались достоверно ниже по сравнению с группой контроля $(\mathrm{p}<0,05)$. Отношение сил дезагрегации к силам агрегации было меньше в группе СД1 по сравнению с группой контроля $(\mathrm{p}<0,005)$. При СД2 силы агрегации эритроцитов были выше по сравнению с группой контроля $(\mathrm{p}<0,005)$. Силы дезагрегации эритроцитов в группе СД2 были также выше в тенденции (p=0,05). Отношения сил дезагрегации к силам агрегации эритроцитов при СД2 с высокой достоверностью были ниже по сравнению с группой контроля $(\mathrm{p}<0,005)$. При этом отношения сил дезагрегации к силам агрегации при СД1 и СД2 не отличались. Заключение. Как для СД1, так и СД2 характерна гиперагрегация эритроцитов. Однако, учитывая полученные данные, можно предположить, что механизмы такой гиперагрегации различны.

Ключевые слова: агрегация эритроцичтов, дезагрегация эритроцитов, оптический пинцет, сахарный диабет 1 типа, сахарный диабет 2 типа

Для цитирования: Фабричнова А. А., Кочелев В. Б., Мисникова И. В., Ковалева Ю. А., Семенов А. Н., Луговиов А. Е., Каданова И. М., Незнанов А. И., Приезжев А. В. Исследование сил парного взаимодействия эритрочитов при их агрегации методом оптического захвата при сахарном диабете 1 и 2 типов. Регионарное кровообращение и микроциркуляция. 2021;20(1):77-83. Doi: 10.24884/1682-6655-2021-20-1-77-83.

UDC $616.155 .1-008.1$

DOI: $10.24884 / 1682-6655-2021-20-1-77-83$

A. A. FABRICHNOVA', V. B. KOSHELEV², I. V. MISNIKOVA ${ }^{2}$, Y. A. KOVALEVA ${ }^{2}$, A. N. SEMENOV ${ }^{1}$, A.E.LUGOVTSOV ${ }^{1}$,I.M.KADANOVA' ${ }^{1}$, A.I. NEZNANOV' ${ }^{1}$, A. V. PRIEZZHEV ${ }^{1}$

\title{
Assessment of the forces of pair interaction of erythrocytes during their aggregation by the optical tweezers in Type 1 and Type 2 diabetes mellitus
}

\footnotetext{
${ }^{1}$ Lomonosov Moscow State University, Moscow, Russia

1, Leninskie Gory, Moscow, Russia, 119991

${ }^{2}$ Moscow Regional Research and Clinical Institute ( MONIKI»), Moscow, Russia

61/2, Schepkina str., Moscow, Russia, 129110

E-mail: anastasia.fabrichnova@mail.ru
}

Summary

Received 30.11.20; accepted 15.01.21

Objective. Measurement and comparison of the aggregation and disaggregation forces of individual erythrocytes during the formation or breakdown of a paired aggregate in vitro in the blood of patients with type 1 diabetes mellitus (T1DM) and type 2 dia- 
betes mellitus (T2DM) using the optical tweezers method. Materials and methods. A total of 50 people were included in the study. Of these, 10 people with T1DM (aged 28 \pm 15.8 ), 26 people with T2DM (aged 66 \pm 13 ). The control group consisted of 14 apparently healthy volunteers $(46 \pm 21$ years old). Measurements of the forces of pair interaction of erythrocytes in a diluted suspension were carried out in vitro by the method of dual-channel optical tweezers. The force of aggregation of erythrocytes FA (pN) and the force of disaggregation FD $(\mathrm{pN})$ were measured and their ratio FD/FA was calculated. Results. The erythrocyte aggregation forces in the T1DM group did not differ significantly from the control group. However, the forces of disaggregation in the T1DM group were significantly lower than in the control group $(p<0,05)$. The ratio of the forces of disaggregation to the forces of aggregation was lower in the T1DM group compared to the control group $(p<0.005)$. In T2DM group, erythrocyte aggregation forces were higher compared to the control group $(p<0.005)$. The erythrocyte disaggregation forces in the T2DM group were also higher $(p=0.05)$. The ratios of the forces of disaggregation to the forces of aggregation of erythrocytes in T2DM group were significantly lower than in the control group $(\mathrm{p}<0.005)$. At the same time, the ratios of the forces of disaggregation to the forces of aggregation in T1DM group and T2DM group did not differ. Conclusion. Both T1DM group and T2DM group are characterized by hyperaggregation of erythrocytes. However, given the data obtained, it can be assumed that the mechanisms of such hyperaggregation are different.

Keywords: erythrocyte aggregation, erythrocyte disaggregation, optical tweezers, type 1 diabetes mellitus, type 2 diabetes mellitus

For citation: Fabrichnova A. A., Koshelev V. B., Misnikova I. V., Kovaleva Y. A., Semenov A. N., Lugovtsov A. E., Kadanova I. M., Neznanov A. I., Priezzhev $A$. V. Assessment of the forces of pair interaction of erythrocytes during their aggregation by the optical tweezers in Type 1 and Type 2 diabetes mellitus. Regional blood circulation and microcirculation. 2021;20(1):77-83. Doi: 10.24884/1682-6655-2021-20-1-77-83.

\section{Введение}

Сахарный диабет (СД) - это группа метаболических заболеваний, при которых хроническая гипергликемия приводит к развитию патологии со стороны большинства органов и систем. Распространенность сахарного диабета стремительно растет. Так, по данным Всемирной организации здравоохранения (ВОЗ), мировой уровень заболеваемости СД с 1980 по 2014 г. увеличился практически вдвое (с 4,7 до 8,5\%) [1]. Поздние осложнения сахарного диабета развиваются, в первую очередь, вследствие поражения сосудистой системы в виде специфического поражения сосудов диабетической микроангиопатии и макроангиопатии, представляющей собой ускоренный атеросклеротический процесс. Однако при СД также наблюдается нарушение реологических свойств крови (от гр. rhe'os «течение, поток»), определяющих текучесть крови в сосудистой системе.

Эффективность работы системы кровообращения достигается благодаря сложным образом организованной регулировке кровотока на уровне микрососудов. В условиях сравнимости просвета микрососудов и характерных размеров форменных элементов крови кровоток можно рассматривать как движение эритроцитов, способных к деформации и агрегации [2].

Эритроциты несут на своей поверхности отрицательный заряд, что обуславливает наличие электростатических сил отталкивания между ними. Под действием внешних факторов, таких как напряжение сдвига в потоке крови, эритроциты сближаются и преодолевают отталкивающие силы, агрегируя друг с другом. В процессе образования агрегатов происходит парное взаимодействие клеток. При приведении двух эритроцитов в непосредственный контакт возникает сила агрегации, не зависящая от внешних сил, которая способствует образованию парного агрегата, что может протекать как «наползание» одной клетки на другую или как «схлопывание» их поверхностей после частичного контакта [3]. Агрегация является обратимым процессом: в норме в кровотоке непрерывно происходит динамический процесс агрегации и дезагрегации эритроцитов. Для разделения образовавшегося парного агрегата необходимо приложить силу дезагрегации. Эритроцитарные агрегаты дезагрегируют в потоке под действием сдвиговых сил.
Факторами, которые способствуют дезагрегации, являются электростатическое отталкивание между клетками, упругие силы мембраны эритроцита. Силы взаимодействия эритроцитов при агрегации и дезагрегации могут отличаться по величине.

Способность эритроцитов к агрегации зависит от многих факторов. Среди них - гемодинамические, концентрация плазменных белков (в основном фибриногена, макроглобулинов, альбумина), электростатические. Важную роль в агрегации клеток играют вязкоупругие свойства мембраны клетки, деформируемость и форма эритроцита. Установлено, что на агрегацию эритроцитов могут влиять различные взаимодействия с рецепторным аппаратом клетки. Показана возможность рецепторного взаимодействия фибриногена с эритроцитами в процессах их агрегации [4]. Также показано, что стимуляция $\alpha$ - и $\beta$-агонистами адренорецепторов (в бо́льшей степени а-агонистами) стимулирует агрегацию эритроцитов [5].

Существование эритроцитарных агрегатов в норме доказано в венозной части сосудистой системы, где сдвиговые скорости потока низки.При выраженной патологической агрегации появление эритроцитарных агрегатов наблюдается в артериолах. Патологическая агрегация, увеличивая неравномерность распределения эритроцитов по сетям микрососудов, приводит к нарушению локального кровоснабжения, снижению скорости кровотока, может препятствовать вхождению клеток в капилляры и способствовать шунтированию эритроцитов по более широким сосудам, в обход капиллярных сетей, увеличивая вероятность развития зон локальной гипоксии [6].

Существует точка зрения, что именно гиперагрегация эритроцитов является наиболее важным гемореологическим нарушением у пациентов с плохим гликемическим контролем при СД. Показано, что патологическая агрегация может служить причиной сосудистых нарушений у больных СД, не имеющих специфических сосудистых осложнений - диабетических микро- и макроангиопатий [7]. Нарушение реологических свойств крови, а также гемостаза на фоне гипергликемии является причиной снижения скорости капиллярного кровотока при СД [8].

Показано, что способность эритроцитов к агрегации находится в прямой зависимости от уровня 
ОРИГИНААЬНЫЕ СТАТЬИ (экспериментальные исслеАования) / ORIGINAL ARTICLES (experimental investigations)

Таблица 1

Распределение больных СД1 и СД2, группы контроля по числу исследованных лиц, полу, возрасту

Table 1

Distribution of patients with T1DM and T2DM, control group by the number of individuals studied, by gender, by age

\begin{tabular}{l|c|c|c}
\hline \multicolumn{1}{c|}{ Показатель } & СД1 & СД2 & Контроль \\
\hline Всего больных & 10 & 26 & 14 \\
\hline Женщины, $\mathrm{n}(\%)$ & $6(60)$ & $16(62)$ & $3(21)$ \\
\hline Мужчины, $\mathrm{n}(\%)$ & $4(40)$ & $10(38)$ & $11(79)$ \\
\hline Возраст, лет (средний возраст, лет) & $21-44(28 \pm 15,8)$ & $49-81(66 \pm 13)$ & $25-67(46 \pm 21)$
\end{tabular}

глюкозы в крови [9]. Хроническая гипергликемия приводит к дестабилизации липидного бислоя, нарушению белок-липидных взаимодействий, модификации цитоскелета эритроцита, изменению ионотранспортных мембранных систем, изменению мембрано-рецепторных комплексов, нарушению процессов энергообеспечения клетки, интенсификации перекисного окисления липидов [10]. Нарушения структуры мембраны эритроцита ведет к снижению концентрации молекул сиаловых кислот, несущих отрицательный заряд на мембране клетки, что способствует уменьшению сил электростатического отталкивания эритроцитов и повышению их способности к агрегации [11].

Ранее при исследовании способности эритроцитов к агрегации при сахарным диабете различными оптическими методами было показано, что, как при СД1, так и при СД2, агрегация эритроцитов повышается [9, 12-15]. Данные исследования проводились с использованием цельной крови, на большом ансамбле клеток.

Пилотное исследование деформируемости эритроцитов на уровне отдельных клеток методом двухканального оптического пинцета при СД2 было проведено в 2016 г. Rupesh et al. По результатам исследования, деформируемость эритроцитов больных СД2 была значимо ниже по сравнению с контролем [16]. Исследование способности отдельных эритроцитов образовывать парные агрегаты при СД с использованием метода оптического захвата проведено А. Н. Семеновым и др. [17] в Международном лазерном центре МГУ им. М. В. Ломоносова в 2017 г. Исследование включало совместно пациентов с сахарным диабетом 1 типа (СД1) и сахарным диабетом 2 типа (СД2). Согласно полученным данным, сила агрегации эритроцитов у больных СД обоих типов достоверно $(\mathrm{p}<0,05)$ превышала силу агрегации в контрольной группе. Достоверных отличий между СД и группой контроля при измерении силы дезагрегации выявлено не было. Подобные результаты получены также А. И. Масляницыной и др. [18] на подгруппе пациентов с СД2 и артериальной гипертензией: при оценке сил взаимодействия отдельных эритроцитов методом оптического захвата отмечалось увеличение силы агрегации эритроцитов.

Однако до сих пор исследования агрегационнодезагрегационных сил эритроцитов на уровне отдельных клеток при сахарном диабете 1 и 2 типов раздельно не проводились.
Целью исследования явилось измерение и сравнение сил агрегации и дезагрегации отдельных эритроцитов при образовании или разделении парного агрегата (дублета) in vitro в крови больных СД1 и СД2 с использованием метода двухканального оптического захвата.

\section{Материалы и методы исследования}

Всего в исследование были включены 50 пациентов. Среди них 10 пациентов с сахарным диабетом 1 типа, 26 пациентов с сахарным диабетом 2 типа, 14 практически здоровых добровольцев, сопоставимых по полу и возрасту. Более подробное распределение исследуемых групп по полу и возрасту приведено в табл. 1.

Исследование гемореологических показателей проводили в образцах венозной крови, взятой из локтевой вены натощак. Кровь стабилизировали в пластиковых пробирках с EDTA (0,002 г/мл), сохраняя при температуре $23{ }^{\circ} \mathrm{C}$. Измерение проводилось в течение 3 ч после взятия пробы, в стеклянной микрокювете толщиной 100 мкм, в которую помещался образец суспензии эритроцитов в аутологичной плазме. Измерения проводили при комнатной температуре. Для каждого приготовленного образца измерения повторялись не менее чем на 15 парах различных эритроцитов. Итоговые результаты были получены после усреднения измеренных значений.

Измерение сил взаимодействия эритроцитов с помошью лазерного пиниеета. Для измерения сил взаимодействия двух одиночных эритроцитов использовался метод оптического захвата, реализованный при помощи двухканального лазерного пинцета $[19,20]$.

В качестве источников излучения использовали два Nd:YAG-лазера (длина волны - 1064 нм, выходная мощность - 200 мВт). Один лазерный пучок всегда неподвижен, на пути второго пучка установлено зеркало, вращение которого позволяет перемещать область фокусировки пучка. Регулировка мощности пучка осуществляется при помощи полуволновых пластинок, установленных после лазера. Перед проведением измерений выполняется калибровка установки. Подробным образом методика измерения при помощи двухканального лазерного пинцета описана в статье [17].

При измерении сил агрегации и дезагрегации эритроцитов два эритроцита захватываются подвижным и неподвижным пучками ловушки. При этом клетки поднимаются со дна кюветы и ориентируются параллельно друг другу (рис. 1, шаг 1). 


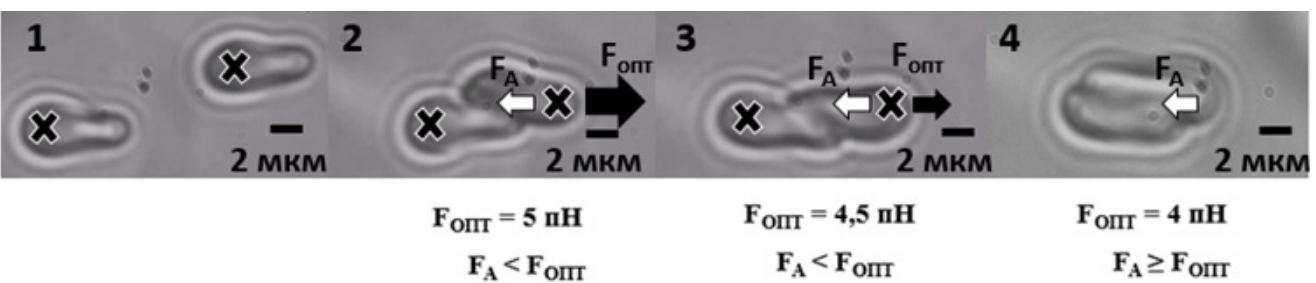

Рис. 1. Схема измерения силы агрегации эритроцитов. Крестовыми метками указаны положения оптических ловушек, стрелки указывают направления приложенных сил

$$
\left(\mathrm{F}_{\mathrm{A}} \text { - белая стрелка; } \mathrm{F}_{\text {опт }}\right. \text { - черная стрелка) }
$$

Fig. 1. Scheme for measuring the aggregation force of erythrocytes. Cross marks indicate the positions of optical traps, arrows indicate the directions of applied forces $\left(\mathrm{F}_{\mathrm{A}}-\right.$ white arrow; $\mathrm{F}_{\text {опт }}-$ black arrow)

Таблица 2

Результаты измерений сил взаимодействия пар эритроцитов при их агрегации и дезагрегации в норме, при СД1, СД2

Table 2

The results of measurements of the forces of interaction of erythrocytes during their aggregation and disaggregation in normal conditions, in T1DM, T2DM

\begin{tabular}{l|c|c|c|c|c}
\hline \multicolumn{1}{c|}{ Показатель } & Контроль & СД1 & p & СД2 & p \\
\hline Сила агрегации эритроцитов FA, пH & $3,0[1,4 ; 3,9]$ & $2,9[2,5 ; 4,0]$ & 0,9 & $4,3[3,5 ; 5,2]$ & 0,002 \\
\hline Сила дезагрегации эритроцитов FD, пН & $5,0[4,1 ; 6,2]$ & $4,2[3,3 ; 4,8]$ & 0,04 & $5,5[4,7 ; 7,0]$ & 0,05 \\
\hline Отношение средних величин & $1,7[1,4 ; 2,2]$ & $1,3[1,2 ; 1,4]$ & 0,007 & $1,3[1,2 ; 1,4]$ & 0,001
\end{tabular}

П р и м е ч а н и е: для каждой величины указаны медиана и квартили [25 \%, 75 \%].

Далее эритроциты приводятся в контакт так, что область их соприкосновения составляет $40 \%$ от длины каждой клетки (рис. 1, шаг 2). Мощность пучка уменьшается до тех пор, пока удерживающей силы со стороны ловушки - силы оптического захвата ( $\left.\mathrm{F}_{\text {опт }}\right)$ (черная стрелка на рис. 2) - становится недостаточно для преодоления спонтанной агрегации эритроцитов (сила агрегации на рис. 2 обозначена белой стрелкой). Клетка вырывается из ловушки, и начинается процесс агрегации клеток. Значение мощности ловушки в момент начала агрегации фиксируется и по калибровочной кривой сопоставляется с силой оптического захвата в этот момент, который и соответствует силе агрегации $\left(\mathrm{F}_{\mathrm{A}}\right)$.

Измерение силы дезагрегации $\left(\mathrm{F}_{\mathrm{D}}\right)$ - минимальной силы, необходимой для разделения парного агрегата эритроцитов, - включает в себя три последовательных шага. 1-й и 2-й шаги идентичны процессу измерения $\mathrm{F}_{\mathrm{A}}$. На 3-м шаге, после приведения клеток в контакт, подвижная оптическая ловушка перемещалась таким образом, чтобы попытаться разделить дуплет. При каждой новой попытке мощность лазера уменьшалась до минимального значения, когда силы оптического захвата недостаточно для дезагрегации дуплета. Это значение силы оптического захвата фиксировалось. Значения больше данной пороговой силы оптического захвата при этом представляют собой силу дезагрегации.

Для сопоставления сил агрегации и дезагрегации вводился параметр $R$, задаваемый отношением средних величин сил дезагрегации и агрегации отдельных эритроцитов:

$$
R=\frac{<F_{D}>}{<F_{A}>}
$$

Этот параметр рассчитывался для каждого образца крови и далее усреднялся по всей группе.
Полученные средние значения R сравнивались между контрольной группой и группой с СД1 и СД2.

Статистическая обработка. Статистическая обработка результатов проводилась с применением пакета прикладных программ «SPSS Statistics 15.0» (IBM). Для количественной оценки данных вычисляли статистические показатели: медиана, 25 \%-й и 75 \%-й квартили (Мe [25 \%, 75 \%]). При сравнении групп пациентов применяли непараметрический критерий Манна - Уитни для сравнения двух независимых признаков. Результаты считались статистически значимыми при $\mathrm{p}<0,05$.

\section{Результаты исследования и их обсуждение}

Результаты исследования приведены в табл. 2.

После статистической обработки данных получены следующие результаты: при СД1 значение сил агрегации эритроцитов $\left(\mathrm{F}_{\mathrm{A}}, \Pi \mathrm{H}\right)$ значимо не отличалось от группы контроля: $\mathrm{F}_{\mathrm{A}}$ при СД1 2,9 [2,5; 4,0] пН, $\mathrm{F}_{\mathrm{A}}$ в группе контроля $3,0[1,4 ; 3,9] \Pi \mathrm{H}(\mathrm{p}=0,9)$. Однако силы дезагрегации в группе СД1 оказались достоверно ниже: $\mathrm{F}_{\mathrm{D}}$ при СД1 - 4,2 [3,3; 4,8] пН, $\mathrm{F}_{\mathrm{D}}$ в группе контроля - 5,0 $[4,1 ; 6,2]$ пН $(\mathrm{p}=0,04)$. Отношение величин сил дезагрегации к силам агрегации $\mathrm{R}=<\mathrm{F}_{\mathrm{D}} / \mathrm{F}_{\mathrm{A}}>$ с высокой достоверностью отличалось между СД1 и группой контроля: СД $1 \mathrm{R}=1,3[1,2 ; 1,4]$, в группе контроля $\mathrm{R}=1,7$ [1,4; 2,2], $\mathrm{p}=0,002$ (результаты приведены на рис. 2).

При сравнении данных, полученных при исследовании образцов СД2 и группы контроля, силы агрегации эритроцитов при СД2 были выше и с высокой достоверностью отличались от группы контроля $\left(\mathrm{F}_{\mathrm{A}}(\mathrm{CД} 2)-4,3[3,5 ; 5,2]\right.$ п $\mathrm{H}, \mathrm{F}_{\mathrm{A}}$ (контроль $)-3,0[1,4$; $3,9] \Pi H, p=0,002$. Силы дезагрегации эритроцитов были в тенденции выше в группе СД2, по сравнению 
ОРИГИНААЬНЫЕ СТАТЬИ (экспериментальные исслеАования) / ORIGINAL ARTICLES (experimental investigations)

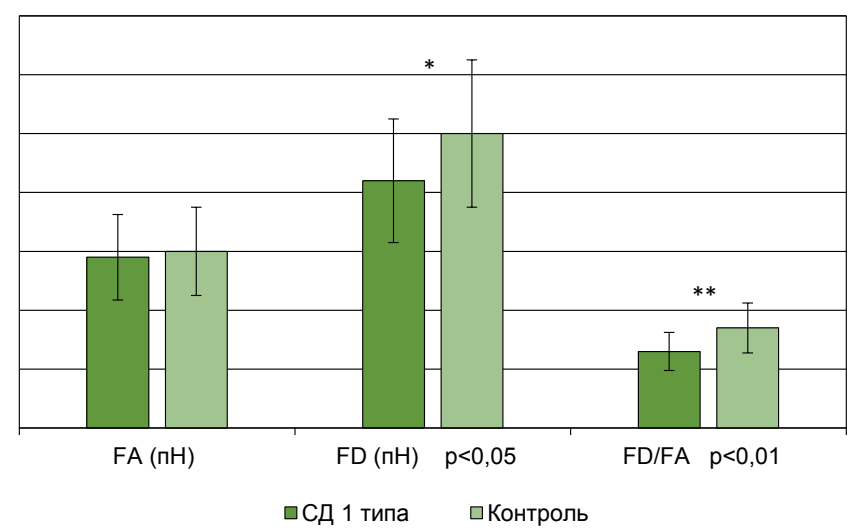

Рис. 2. Силы агрегации и дезагрегации одиночных эритроцитов крови пациентов с СД1 и контрольной группы

Fig. 2. Forces of aggregation and disaggregation of single erythrocytes in blood of patients with type 1 diabetes mellitus and in the control group

с группой контроля: $\mathrm{F}_{\mathrm{D}}(\mathrm{CД} 2)-5,5[4,7 ; 7,0]$ пH, $\mathrm{F}_{\mathrm{D}}$ (контроль) $-5,0[4,1 ; 6,2] \Pi \mathrm{H}, \mathrm{p}=0,05$. Сравнение отношения сил дезагрегации к силам агрегации $\mathrm{R}=<\mathrm{F}_{\mathrm{D}} /$ $\mathrm{F}_{\mathrm{A}}>$ эритроцитов обеих групп при СД2 и в группе контроля показало, что так же, как и в случае СД1, отношение R с высокой достоверностью ниже у больных $\mathrm{CД} 2$, по сравнению с группой контроля. $\mathrm{R}(\mathrm{CД} 2)=1,3$ $[1,2 ; 1,4] \Pi \mathrm{H}, \mathrm{R}$ (контроль) $=1,7[1,4 ; 2,2] \Pi \mathrm{H}, \mathrm{p}=0,001$ (результаты показаны на рис. 3).

Таким образом, в ходе эксперимента, как при СД1, так и при СД2, наблюдалось смещение равновесия процесса агрегации-дезагрегации в сторону гиперагрегации. При СД1 гиперагрегация наблюдалась за счет снижения сил дезагрегации при неизменной силе агрегации, а при СД2 силы агрегации были с высокой достоверностью выше нормы, силы дезагрегации превышали норму в тенденции $(\mathrm{p}=0,05)$. Полученные данные могут говорить о существовании различных механизмов нарушения процессов агрегации-дезагрегации эритроцитов при СД1 и СД2.

Различие в механизмах гиперагрегации возможно объяснить существенным отличием в патогенезе и особенностях лечения диабетов обоих типов. СД1 и СД2 - это два различных заболевания, объединенных в одну группу на основании наличия гипергликемии. При СД1 наблюдается абсолютная недостаточность инсулина, вследствие чего развивается гипергликемия, и основные патофизиологические последствия СД1 связаны с глюкозотоксичностью.

При СД2 пусковым фактором, присутствующим еще до манифестации заболевания, является инсулинорезистентность. Показано, что инсулинорезистентность самостоятельно связана с повышением способности эритроцитов к агрегации [21]. Инсулинорезистентность, наряду с ожирением, является основой развития метаболического синдрома, на фоне которого в большинстве случаев развивается СД2. При метаболическом синдроме наблюдаются нарушения липидного, пуринового, углеводного обменов, повышение провоспалительного статуса организма, уровня фибриногена, макроглобулинов, что приводит к нарушению реологических свойств крови и повышению агрегации эритроцитов $[22,23]$. По некоторым данным, повышение уровня фибриногена играет при этом

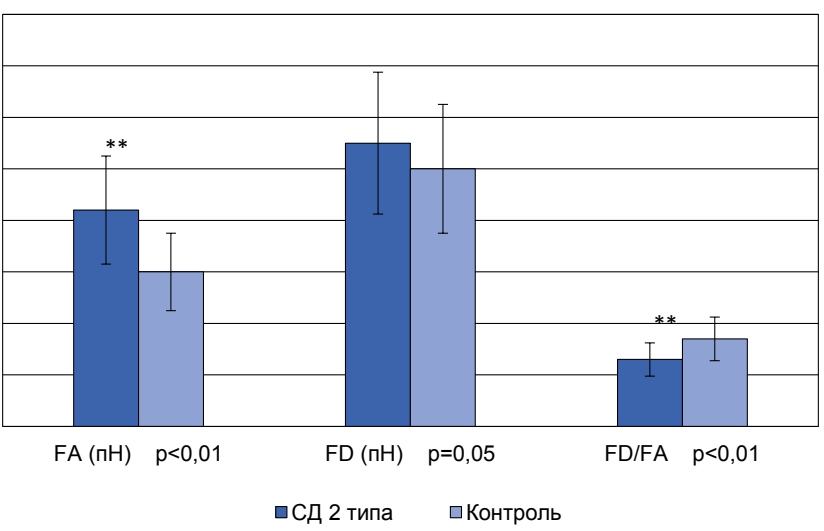

Рис. 3. Силы агрегации и дезагрегации одиночных эритроцитов в крови пациентов с СД2 и контрольной группы

Fig. 3. Forces of aggregation and disaggregation of single erythrocytes in blood of patients with type 2 diabetes mellitus and in the control group

наиболее важную роль в развитии гиперагрегации эритроцитов [24]. Избыточное включение липидов в мембраны эритроцитов при дислипидемии ведет к нарушению асимметрии липидов в бислое мембран, повышению перекисного окисления липидов, вследствие чего происходит потеря мембранами клеток их вязкоупругих свойств, снижение отрицательного заряда мембраны и, как следствие, нарушение микрореологических свойств эритроцитов [25].

Однако было показано, что при введении больным СД2 инсулина в различных концентрациях (в том числе в физиологической) наблюдается снижение гиперагрегации эритроцитов [26]. В другом эксперименте пациентам с СД2, получающим инсулин в качестве терапии, введение инсулина in vivo снижало агрегацию эритроцитов до нормы, а также снижало агрегацию эритроцитов у лиц без диабета [27].

Анализируя полученные экспериментальные и литературные данные, можно предположить, что наблюдаемое в опыте снижение сил дезагрегации при нормальной агрегации эритроцитов у больных СД1 может быть связано с улучшением агрегации эритроцитов при введении инсулина (который с необходимостью присутствует в терапии данных больных). Кроме того, больные СД1 не имеют метаболического синдрома с сопутствующими ему дополнительными патологическими факторами, способствующими гиперагрегации эритроцитов. Одним из механизмов снижения сил дезагрегации при СД1 может быть снижение отрицательного заряда мембран эритроцитов и, соответственно, сил электростатического отталкивания клеток, наблюдаемого при гипергликемии [11].

Стоит отметить, что исследования на ансамбле клеток у больных СД1, как правило, указывают на повышение способности эритроцитов к агрегации $[9,12-15]$. Однако при наиболее распространенных оптических методах исследования, таких, например, как метод диффузного светорассеяния, оцениваемые параметры агрегации (размер, прочность эритроцитарных агрегатов, кинетика агрегации и др.) являются результирующей отношения сил дезагрегации-агрегации, в то время как метод оптического захвата позволяет измерить данные силы раздельно для обоих процессов. В целом такой же результат (повышение 
способности эритроцитов к агрегации) получен и в ходе данного эксперимента, однако за счет снижения сил дезагрегации эритроцитов.

Больные СД2, «отягощенные» метаболическим синдромом, могут иметь более существенный спектр причин для нарушения микрогемореологических свойств эритроцитов, кроме глюкозотоксичности: инсулинорезистентность, гиперлипидемия, повышение уровня провоспалительных глобулинов, более высокий уровень фибриногена. Кроме того, такие больные, как правило, не получают инсулин в составе терапии. Результаты эксперимента говорят о наличии повышения способности эритроцитов к агрегации при СД2 с высокой достоверностью $(p=0,002)$ и увеличении сил, необходимых для дезагрегации дуплета эритроцитов в тенденции $(\mathrm{p}=0,05)$. Поскольку агрегация и дезагрегация, несмотря на функционально различную природу, являются сторонами единого процесса, одновременное увеличение сил агрегации и дезагрегации выглядит логичным.

\section{Выводы}

Таким образом, в ходе эксперимента было показано следующее.

1. Как при СД1, так и при СД2, в процессе парной агрегации-дезагрегации эритроцитов результирующие силы процесса агрегации выше по сравнению с нормой с высокой достоверностью.

2. При СД1 агрегация не отличалась от нормы, при этом силы дезагрегации были достоверно ниже нормы.

3. У больных СД2 как силы агрегации, так и силы дезагрегации превышали норму.

4. Полученные отношения сил дезагрегации и агрегации при СД1 и СД2 не отличались между собой.

5. Учитывая полученные данные, можно предположить, что механизмы гиперагрегации при СД1 и СД2 различны.

Дальнейшие исследования сил взаимодействия эритроцитов при СД1 и СД2 и патогенеза процесса агрегации-дезагрегации требуются для получения более полных данных.

\section{Финансирование / Acknowledgments}

Работа выполнена при финансовой поддержке гранта РФФИ № 19-52-51015. / This work was carried out with the financial support of the RFBR grant No. 1952-51015.

\section{Конфмикт интересов / Conflict of interest}

Авторы заявили об отсутствии конфликта интересов. / The authors declare no conflict of interest.

\section{Аитература / References}

1. Global report on diabetes / World Health Organization. Geneva, 2018.

2. Соколова И. А. Агрегащия эритрочитов// Регионарное кровообращение и микрочиркуляичя. - 2010. - № 4. - C. 4-6. [Sokolova I. A. Aggregation of erythrocytes. Regional blood circulation and microcirculation. 2010;(4):4-6. (In Russ.)].

3. Khokhlova MD, Lyubin EV, Zhdanov AG, Rykova SYu, Krasnova TN, Sokolova IA, Fedyanin AA. Peculiarities of RBC aggregation studied by double trap optical tweezers. Proc. of SPIE. 2010 Apr;7715(0M):1-8. Doi: 10.1117/12.854502
4. Соколова И. А., Рыкова С. Ю., Шахназаров А. А. и др. Агрегачия эритроцитов: некоторые вопросы и гипотезы // Рос. жур. биомеханики. - 2011. - T. 15, № 1(51). - C. 7-22. [Sokolova IA, Rykova SYu, Shakhnazarov AA, Gafarova ME, Krasnova TN, Khokhlova MD, Lyubin EV, Skryabina MN, Zhdanov AG, Fedyanin AA. Aggregation of erythrocytes: some questions and hypotheses. Russian Journal of Biomechanics. 2011;15(1)51:7-22. (In Russ.)].

5. Муравьев А. В. Муравьев А. А. Вне- и внутриклеточные механизмы изменения агрегации эритроцитов // Физиология человека. - 2005. - Т. 31, № 4. - C. 108-112. [Muravyov AV, Muravyov AA. Extra- and intracellular mechanisms of erythrocyte aggregation changes. Human Physiology. 2005;31(4):108-112. (In Russ.)].

6. Bronkhorst PJ, Grimbergen J, Brakenhoff GJ, Heethaar RM, Sixma JJ. The mechanism of red cell (dis)aggregation investigated by means of direct cell manipulation using multiple optical trapping. Br. J. Haematol. 1997;96(2):256-258.

7. Le Devehat C, Khodabandehlou T, Vimeux M. Impaired hemorheological properties in diabetic patients with lower limb arterial ischaemia. Clin Hemorheol. 2001;25(2):43-48.

8. Barrett-Connor E, Giardina E, Gitt A, Gudat U, Steinberg $H$, Tschoepe D. Women and heart disease: the role of diabetes and hyperglycemia. Arch Intern Med. 2004;164(9):934942. Doi: 10.1001/archinte.164.9.934

9. Babu N, Singh M. Influence of hyperglycemia on aggregation, deformability and shape parameters of erythrocytes. Clin Hemorheol Microcirc. 2004;31(4):273-280.

10. Szablewski L, Sulima A. The structural and functional changes of blood cells and molecular components in diabetes mellitus. Biol Chem. 2017;398(4):411-423. Doi: 10.1515/ hsz-2016-0196.

11. Budak Y, Demirci H, Akdogan MYavuz D. Erythrocyte membrane anionic charge in type 2 diabetic patients with retinopathy. BMC Ophthalmology. 2004;(4):14. Doi: 10.1186/ 1471-2415-4-14.

12. Le Dévéhat $C$, Vimeux $M$, Khodabandehlou T. Blood rheology in patients with diabetes mellitus. Clin Hemorheol Microcir. 2004;(30):297.

13. Young ICh, Mooney MP, Daniel JCh. Hemorheological disoders in Diabetes Mellitus. Journal of Diabetes Science and Technology. 2006;2(6):24-28 Doi: 10.1177/ 193229680800200622.

14. Torregiani F, Umansky-Zeverin M, Riqueline B, Rasia $R$. Hemorheological alterations in diabetic patients. Clin Hemorheol. 1995;(15):687. Doi: 10.1530/endoabs.37.EP442

15. Singh $M$, Shin S. Changes in erythrocyte aggregation and deformability in diabetes mellitus: A brief review. Indian Journal of Experimental Biology. 2009;47(1):7-15.

16. Agrawal R, Smart T, Nobre-Cardoso J, Richards Ch, Bhatnagar Rh, Tufail A, Shima D, Jones PhI, Pavesio C. Assessment of red blood cell deformability in type 2 diabetes mellitus and diabetic retinopathy by dual optical tweezers stretching technique. Sci. Rep. 2016 Mar15;(6):15873. Doi: 10.1038/srep 15873 .

17. Семенов А. Н., Луговиов А. Е., Ли К. и др. Использование методов диффузного рассеяния света и оптического захвата для исследования реологических свойств крови: агрегация эритроцитов при сахарном диабете // Изв. Сарат. ун-та. Сер.: Физика. - 2017. - Т. 17, № 2. C. 85-97. [Semenov AN, Lugovtsov AE, Li K, Fabrichnova AA, Priezzhev AV. Applying Methods of Diffuse Light Scattering and Optical Trapping for Assessing Blood Rheological Parameters: Erythrocytes Aggregation in Diabetes Mellitus. Izv. Sarat. un. New ser. Ser. Physics 2017;17(2):85-97. (In Russ.)].

18. Маслянииына А. И., Каданова И. М., Незнанов А. И. и др. Микрореологические свойства крови и капиллярный 
кровоток при артериальной гипертензии и сахарном диабете второго типа: исследование оптическими методами in vitro u in vivo // Комплексные проблемы сердечно-сосудистых заболев. - 2020. - T. 9, № 2. - C. 53-63. [Maslyanitsyna AI, Kadanova IM, Neznanov AI, Ermolinsky PB, Gurfinkel YuI, Pigurenko AA, Dyachuk LI, Lugovtsov AE, Priezzhev AV. Microrheological properties of blood and capillary blood flow in arterial hypertension and type 2 diabetes mellitus: study by optical methods in vitro and in vivo. Complex problems of cardiovascular diseases. 2020;9(2):53-63. (In Russ.)]. Doi: 10.17802 / 2306-1278-2020-9-2-53-63.

19. Lee K, Kinnunen M, Khokhlova MD, Lyubin EV, Priezzhev AV, Meglinski I, Fedyanin AA. Optical tweezers study of red blood cell aggregation and disaggregation in plasma and protein solutions. J. Biomed. Opt., 2016;21(3):035001. Doi: 10.1117/1.JBO.21.3.035001.

20. Fernandes PH, Fontes A, Thomaz A, Castro V, Cesar CL, and Barjas-Castro ML. Measuring red blood cell aggregation forces using double optical tweezers. Scand J Clin Lab Invest. 2013;73(3):262-264. Doi: 10.3109/00365513.2013.765961.

21. Brun JF, Varlet-Marie E, Raynaud de Mauverger E. Relationships between insulin sensitivity measured with the oral minimal model and blood rheology. Clin Hemorheol Microcirc. 2012;51(1):29-34. Doi: 10.3233/CH-2011-1426.

22. Toker S, Rogowski O, Melamed S, Shirom A, Shapira I, Berliner S, Zeltser D. Association of components of the metabolic syndrome with the appearance of aggregated red blood cells in the peripheral blood. An unfavorable hemorheological finding. Diabetes Metab Res Rev. 2005 Mar-Apr; 21(2):197202. Doi: 10.1002/dmrr.502.

23. Gyawali P, Richards RS, Hughes DL, Tinley P. Erythrocyte aggregation and metabolic syndrome. Clin Hemorheol Microcirc. 2014;57(1):73-83. Doi: 10.3233/CH-131792.

24. Schechner V, Shapira I, Berliner S, Comaneshter D, Hershcovici T, Orlin J, Zeltser D, Rozenblat M, Lachmi K, Hirsch M, Beigel Y. Significant dominance of fibrinogen over immunoglobulins, $C$-reactive protein, cholesterol and triglycerides in maintaining increased red blood cell adhesiveness/aggregation in the peripheral venous blood: a model in hypercholesterolaemic patients. Eur J Clin Invest. 2003Nov;33(11):955961. Doi: 10.1046/j.1365-2362.2003.01260.x.

25. Torregiani F, Umansky-Zeveri M, Riqueline B, Rasia R. Hemorheological alterations in diabetic patients. Clin. Hemorheol. 1995;(15):687-690.

26. Coppola L, Verrazzo G, La Marca C, Ziccardi P, Grassia A, Tirelli A, Giugliano D. Effect of insulin on blood rheology in non-diabetic subjects and in patients with Type 2 diabetes mellitus. Diabet Med. 1997;14(11):959-963. Doi: 10.1002/(SICI)10969136(199711)14:11<959::AID-DIA499>3.0.CO;2-U .

27. Mantskava M, Pargalava N, Mchedlishvili G. Direct beneficial effect of insulin on blood rheological disorders in the microcirculation. Clin Hemorheol Microcirc. 2004;30(3-4):431-433.

\section{Информация об авторах}

Фабричнова Анастасия Анатольевна - ассистент кафедры терапии Факультета фрундаментальной медицины, Московский государственный университет им. М. В. Аомоносова, Москва, Россия, e-mail: anastasia.fabrichnova@mail.ru.

Кошелев Влахимир Борисович - $\Delta-р$ биол. наук, зав. кадеАрой фризиологии и общей патологии Факультета фрунАаментальной медицины, Московский государственный университет им. М. В. Аомоносова, Москва, Россия, e-mail: vkoshelev@ fbm.msu.ru.

Мисникова Инна Владимировна - - -р мед. наук, ведуший научный сотрудник отАеления терапевтической эндокрино- ^огии, профрессор кафредры эндокринологии, Московский областной научно-исследовательский клинический институт им. М. Ф. Владимирского, Москва, Россия, е-mail: innamisnikova@mail.ru.

Ковалева Юлия Александровна - канд. мед. наук, старший научный сотрудник отАеления терапевтической эндокрино^огии, Московский областной научно-исследовательский к^инический институт им. М. Ф. ВАадимирского, Москва, Россия, e-mail: yulia.kovaleva@mail.ru.

Семенов Алексей Николаевич - аспирант Физического фракультета, Московский государственный университет им. М. В. Аомоносова, Международный мазерный центр Московского государственного университета им. М. В. Аомоносова, Москва, Россия, e-mail: semenov@physics.msu.ru.

Ауговцов Анцрей Егорович - канд. фриз.-мат. наук, научный сотрудник, Физический факультет, Международный лазерный центр Московского государственного университета имени М. В. Аомоносова, Москва, Россия, е-mail: anlug1@ gmail.com.

Кацанова Ирина Михайловна - студент магистратуры, Московский государственный университет им. М. В. Аомоносова, Москва, Россия, e-mail: kadanovairina@mail.ru.

Незнанов Антон Игоревич - студент магистратуры, Физический фракультет, Московский государственный университет им. М. В. Аомоносова, Москва, Россия, e-mail: neznanov.ai@mail.ru.

Приезжев Алексаньр Васияьевич - кань. фриз.-мат. наук, доцент, Физический фракультет, Межлународный лазерный центр Московского государственного университета им. М. В. Аомоносова, Москва, Россия, e-mail: avp2@mail.ru.

\section{Information about authors}

Fabrichnova Anastasia A. - Assistant, Department of Therapy, Faculty of Fundamental Medicine, Moscow State University named after M. V. Lomonosov, Moscow, Russia, e-mail: fabrichnova@mail.ru.

Koshelev Vladimir B. - Doctor of Biological Sciences, Head of the Department of Physiology and General Pathology, Faculty of Fundamental Medicine, Moscow State University, Moscow State University named after M. V. Lomonosov, Moscow, Russia, e-mail: vkoshelev@fbm.msu.ru.

Misnikova Inna V. - Doctor of Medical Sciences, Leading Researcher of the Department of Therapeutic Endocrinology, Professor of the Department of Endocrinology, Moscow Regional Research Clinical Institute named after M. F. Vladimirsky, Moscow, Russia, e-mail: inna-misnikova@mail.ru.

Kovaleva Yulia A. - pHD, Senior Researcher, Department of Therapeutic Endocrinology, Moscow Regional Research Clinical Institute named after M. F. Vladimirskiy, Moscow, Russia, e-mail: yulia.kovaleva@mail.ru.

Semenov Alexey N. - PhD student, Faculty of Physics, Moscow State University named after M. V. Lomonosov, International Laser Center of Moscow State University named after M. V. Lomonosov, Moscow, Russia, e-mail: semenov@physics.msu.ru.

Lugovtsov Andrey E. - PhD in Physics and Mathematics, Researcher, Faculty of Physics, Moscow State University named after M. V. Lomonosov, International Laser Center of Moscow State University named after M. V. Lomonosov, Moscow, Russia, e-mail: anlug1@gmail.com.

Kadanova Irina M. - Master's student, Moscow State University named after M. V. Lomonosov, Moscow, Russia, e-mail: kadanovairina@mail.ru.

Neznanov Anton I. - Master's student, Faculty of Physics, Moscow State University named after M. V. Lomonosov, Moscow, Russia, e-mail: neznanov.ai@mail.ru.

Priezzhev Alexander V. - Candidate of Physical and Mathematical Sciences, Associate Professor, Faculty of Physics, Moscow State University named after M. V. Lomonosov, International Laser Center of Moscow State University named after M. V. Lomonosov, Moscow, Russia, e-mail: avp2@mail.ru. 